\title{
The main trends of computer-aided design systems development
}

\author{
Alexander Ginzburg, Leonid Shilov and Liubov Shilova* \\ Moscow State University of Civil Engineering, Yaroslavskoe shosse, 26, Moscow, 129337, Russia
}

\begin{abstract}
A review of papers in the field of development of automated design systems is presented. For the purpose of evaluation of urgency, importance and prospects of research works in the aforesaid field, the paper also includes the statistics on published works for the last five years. Based on the methods of statistical analysis and comparison, the data from the SCOPUS International Database have been collected. As a result, the main development trend in this direction has been revealed.
\end{abstract}

\section{Introduction}

The abbreviations CAD (computer-aided design) and CADS (computer-aided design system) are now in use in many fields of knowledge, which is proved by a great deal of published research works in popular reference databases.

The realization of the fact that it was possible to improve the efficiency of production of calculations and drawings gave impetus to the development of the process of automation of design works.

It was seen that the solution of that problem would contribute to transition of manpower resources from the field of production to the field of engineering information activities, where the development of automated means for design works became the next logical stage.

It is accepted to subdivide the history of development of CAD systems into several stages.

First stage: the initiation of CAD systems lasted till the end of the 1970s.

Second stage: its rush-years were the 1980s, it was the time of active use of graphics work stations of such companies as Intergraph, Sun Microsystems.

It is interesting that the cost of one CADS license achieved the value of 90000 dollars then, but by the end of that period it reduced to 20000 dollars. This very fact gave impetus to the development of wide use systems: CAD/CFM/CAE systems.

Third stage: it started in early 1990s. The development of electronics, in particular that of microprocessors, allowed the use of computers instead of work stations, which resulted in a considerable reduction of the cost of introduction of CAD systems at industrial works. The license cost lowered to several thousand dollars.

\footnotetext{
* Corresponding author: ShilovaLA@mgsu.ru
} 
Now we have the fourth stage, which started late in 1990s. At this stage, the integration of $\mathrm{CAD} / \mathrm{CFM} / \mathrm{CAE}$ systems with the data control systems and other means of information support in production takes place, and we can see quite a logical trend of development here: an active introduction of information support technologies for buildings and structures at all the stages of their life-cycles in construction.

Besides, it should be noted that, during the process of development of CAD systems in the USSR and then in the RF, two somewhat different approaches have been formed with respect to the point what to consider a CAD system. Traditionally, the CAD systems were developed as the systems of automation of drawing works in the fields of electronics and machine-building. In accordance with that, the research works and papers in the field were mainly devoted to the problems of engineering provision of recognition and representation of graphics images, etc.

\section{Methodology}

Taking into consideration the rate of publication of new research and development works, we realize the necessity of review papers compiling the main achievements in different fields of knowledge. The authors used the method of statistical analysis and that of the comparative one, they compared the statistical data with respect to the amount of published works in the field. The authors estimated the urgency and importance of development of CAD systems, they also revealed the main development trends in the field.

\section{Results}

To review the modern state of development of CAD systems, the authors used the most popular database including recent achievements in different fields of knowledge: SCOPUS (scopus.com). The information has been collected through the key word "CAD system".

The search covered a wide range of items: headings, key words and abstracts for the papers in two closely-related fields of knowledge: engineering and computer science. Altogether, 6442 references has been found in the SCOPUS database (August 2018) including the unpublished papers for 2018 and 2019.

The distribution of published papers with respect to the years of their appearance is presented in Fig.1. 


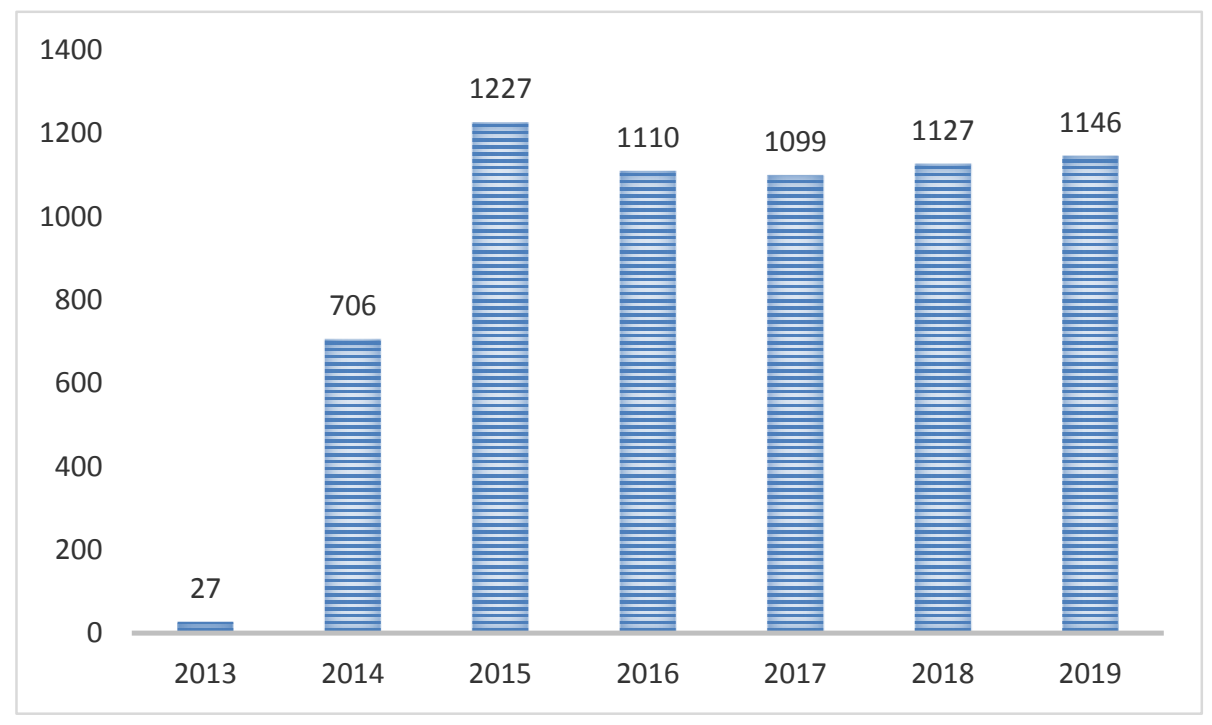

Fig.1. Distribution of published papers with respect to the appearance years.

Table 1 presents the first 20 countries with the most published papers in the field of CAD systems; the authors from these countries published about $91 \%$ of the papers in the field, the percentage of papers for each country is presented in Fig.2.

Table 1. Leading countries in the field of CAD systems with respect to published works (according to the International SCOPUS Database).

\begin{tabular}{|l|c|l|c|}
\hline Country & $\begin{array}{l}\text { Number } \\
\text { publications }\end{array}$ & Country & $\begin{array}{l}\text { Number of } \\
\text { publications }\end{array}$ \\
\hline China & 994 & Russian Federation & 190 \\
\hline United States & 991 & Canada & 176 \\
\hline India & 560 & Malaysia & 158 \\
\hline Germany & 425 & Poland & 152 \\
\hline Italy & 357 & Brazil & 134 \\
\hline United Kingdom & 276 & Taiwan & 127 \\
\hline Japan & 265 & Egypt & 115 \\
\hline France & 235 & Turkey & 104 \\
\hline Spain & 226 & Portugal & 92 \\
\hline South Korea & 191 & Singapore \\
\hline Total : 5858 & \multicolumn{3}{|l}{} \\
\hline
\end{tabular}




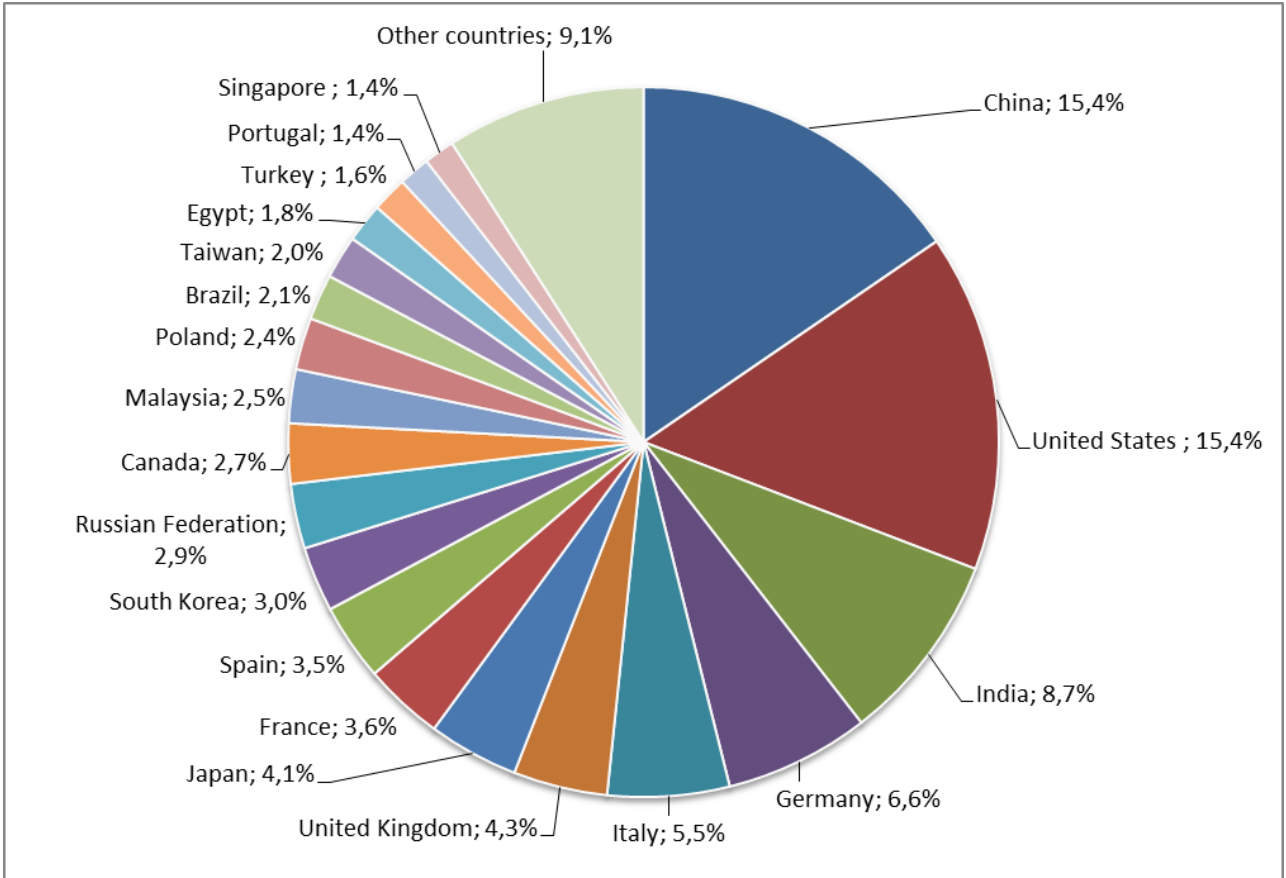

Fig.2. Percentage of works published in the field of CAD systems with respect to the countries.

Fig. 2 shows the leaders in the field of studies of CADS databases: China and the USA (first place), India (second place) and Germany (third place). The Russian authors have only 3\% (190 papers) of the total amount of published works for the period concerned.

However, if we consider (with respect to published papers) not the countries but research centres or universities, the situation becomes somewhat different (Table 2).

Table 2. Leading organizations in the field of CAD systems with respect to published works (according to the International SCOPUS Database).

\begin{tabular}{|c|c|c|c|}
\hline Organization & Country & $\begin{array}{l}\text { Number } \\
\text { publications }\end{array}$ & $\%$ \\
\hline Chinese Academy of Sciences & China & 57 & 0,9 \\
\hline Ministry of Education China & China & 51 & 0,8 \\
\hline Shanghai Jiao Tong University & China & 49 & 0,8 \\
\hline Zhejiang University & China & 44 & 0,7 \\
\hline University of Malaya & Malaysia & 44 & 0,7 \\
\hline Politecnico di Milano & Italy & 42 & 0,7 \\
\hline Politechnika Slaska w Gliwicach & Poland & 41 & 0,6 \\
\hline $\begin{array}{l}\text { Huazhong University of Science and } \\
\text { Technology }\end{array}$ & China & 41 & 0,6 \\
\hline Politecnico di Torino & Italy & 38 & 0,6 \\
\hline Ngee Ann Polytechnic & Singapore & 38 & 0,6 \\
\hline Georgia Institute of Technology & USA & 37 & 0,6 \\
\hline CNRS Centre National de & France & 36 & 0,6 \\
\hline
\end{tabular}




\begin{tabular}{|l|l|l|l|}
\hline Recherche Scientifique & & & \\
\hline Beihang University & China & 36 & 0,6 \\
\hline Technical University of Munich & Germany & 35 & 0,5 \\
\hline $\begin{array}{l}\text { Northwestern Polytechnical } \\
\text { University }\end{array}$ & China & 34 & 0,5 \\
\hline Nanyang Technological University & Singapore & 33 & 0,5 \\
\hline King Saud University & Saudi Arabia & 31 & 0,5 \\
\hline Universita Politecnica delle Marche & Italy & 31 & 0,5 \\
\hline Mansoura University & Egypt & 30 & 0,5 \\
\hline University of Louisville & USA & 29 & 0,5 \\
\hline $\begin{array}{l}\text { Korea Advanced Institute of Science } \\
\text { \& Technology }\end{array}$ & South Korea & 29 & 0,5 \\
\hline
\end{tabular}

At the same time, the Bew Richards model, presented in Fig. 3, distinguishes several levels of development of BIM-technologies. The software analysis proved the fact that nowadays no solution can provide an information support for a construction project at the maintenance stage so far. All that may favour the development of new studies and research works in the field.

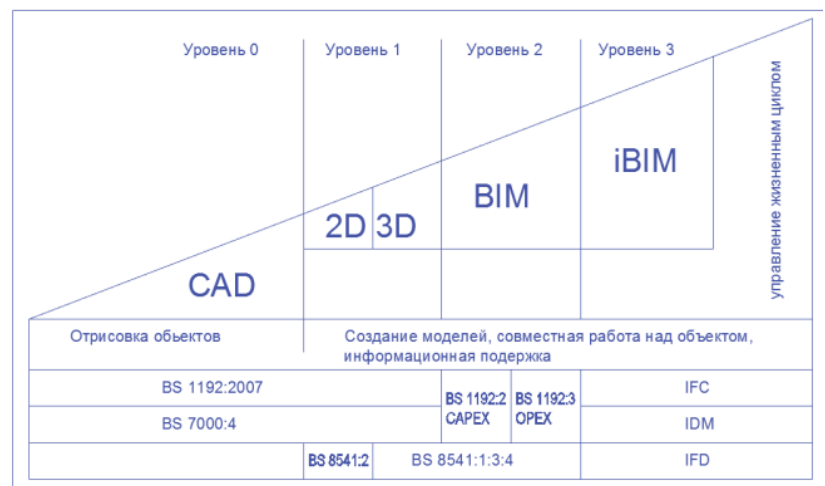

Fig.3. The Bew Richards model of BIM implementation.

In this connection, quite a lot of published papers use the available information concerning CAD systems as a basis for the development of new technologies [2-15, etc].

The published works pay much attention to the questions of reliability and safety of CAD systems as well as to the development of new plug-ins for the design works with intellectual constructions systems.

For instance, the authors of the paper [16] present us a new computer-aided design application for the design of smart building systems based on the installation of hardware nodes across the indoor space. Their tool provides a site-specific algorithm for costeffective deployment of wireless localization systems, with the aim to maximize the localization accuracy. Moreover, the experimental results from real-world environment show that the proposed site-specific model can improve the positioning accuracy of general models from the state-of-the-art. The tool, available open-source, is modular and extensible through plug-ins allowing to model building systems with different requirements

In the work [17], we can find a complex framework, which integrate attribute-level safety risk data within existing technologies for the first time. The framework is demonstrated by integrating attribute safety risk data with information retrieval, location and tracking 
systems, augmented reality and building information models. It is important to notice that this framework is the first attempt to integrate empirical risk-based safety data with construction information technologies.

A series of published works is devoted to the analysis of the use of CAD systems in the field of education

For instance, the work [18] presents the information on the background and differences of CAD and BIM education, and on how the transition from CAD to BIM can be achieved for collaborative working practices. The analysis was performed on freshman and junior level courses to learn the perception of students about CAD and BIM education. A dual-track survey was used to collect responses from AEC students in four consecutive years. The results showed that students prefer BIM to CAD in terms of the friendliness of the userinterface, help functions, and self-detection of mistakes. The survey also revealed that most of the students believed in the need of a BIM specialty course with Construction Management (CM), Structural Engineering (SE), and Mechanical-Electrical-Plumbing (MEP) areas. The benefits and challenges of both CAD- and BIM-based software from students' perspectives help to improve the learning outcomes of CAD/BIM courses to help students in their learning process and work as a guideline for educators on how to design and teach $\mathrm{CAD} / \mathrm{BIM}$ courses simultaneously by considering the learning process and perspectives of students.

The work [19] presents the potentiality of architectural modelling within the study process "Principles of modelling of structural systems".

This article presents the potentialities of architectural modelling in the learning process of Fundamentals of Structural Systems Modelling subject-EAU (Escola de Arquitetura e Urbanismo), incorporating new learning methods, making use of circular reference processes.

The authors want to mention the work [20], where the problems of the use of mobile devices for the acquisition of space visualization skills were studied at the example of students from Belgorod University.

\section{Conclusions}

The collected information testifies to the fact that the interest to the field of studies of CAD systems is high; there are some still unsolved questions in the field and considerable potentialities of the further development of CAD systems.

Besides that, the CAD systems are inseparably linked with BIM-technologies. A BIMmodel may be used at the design and construction stages as well as in the process of maintenance, reconstruction or repair works with buildings and structures. Therefore, it becomes obvious that it is still necessary to solve some research problems for the purpose of an efficient introduction of CAD systems.

The development of CAD systems is also favoured by the fact that nowadays it is possible to use the CAD systems at personal computers through subscription, and it does not cost much.

This work was financially supported by Ministry of Science and Higher Education of the Russian Federation (\#NSh-3492.2018.8).

\section{References}

1. A. Ginzburg, L.Shilova, A. Adamtsevich, L.Shilov, JAES, 14(4), 457-460 (2016)

2. J. Zhou, P.E.D Love, J. Matthews, B.Carey, C.P. Sing, AiC, 49, 142-151 (2015)

3. S. Malsane, J. Matthews, S. Lockley, P.E.D. Love, AiC, 49, 51-58 (2015) 
4. H. Moon, H. Kim, C. Kim, L. Kang, AiC, 39, 93-105 (2014)

5. S.-K. Woo, K.-J. Kim, B.-D. Youn, ISARC 2013, 160-167 (2013)

6. M.L. Xu, Y.G. Fu, AiISaC, 809, 2270-2273 (2019)

7. Y. Wang, Y. Hao, Y. Wang, CSPS 2017, 1975-1983, (2019)

8. S. Porter, T. Tan, X. Wang, V. Pareek, AiC, 94, 85-92 (2018)

9. L. Chow, S. Fai, ISPRS Archives, 42(2W5), 125-128 (2017)

10. G. Wang, J. Song, CiHB, 68, 493-500 (2017)

11. J.C. Pérez-Sánchez, R.T. Mora-García, V.R. Pérez-Sánchez, B. Piedecausa-García, WITTBE, 169, 45-54 ( 2017)

12. I.B. Finnerty, AEI 2017, 867-879 (2017)

13. C. Ellul, G. Boyes, C. Thomson, D. Backes, LNG\&C, 9783319256894, 495-512 (2017)

14. L. Wang, Z. Zhao, X. Wu, IJoCaA, 7, 179-188 (2016)

15. H. Moon, N. Dawood, L. Kang, AEI, 28, 50-65 (2014)

16. A. Cirigliano, R. Cordone, A.A. Nacci, M.D. Santambrogio, 37(1), 133-145 (2018)

17. M.R. Hallowell, D. Hardison, M. Desvignes, CI, 16, 323-347 (2016)

18. G.O. Deniz, JoITiC 23, 138-156 (2018)

19. I. Xavier, P. Cantreva, I. Klein, AiISaC, 809, 1777-1788 (2019)

20. A. Trifunović, S. Čičević, D. Lazarević, M. Dragović, A. Čučaković, AiISaC, 809, 1740-1750 (2019) 